Int. J. Dev. Biol. 57: 439-443 (2013)

doi: $10.1387 / \mathrm{ijdb} .120215$ ty

\title{
Germes is involved in translocation of germ plasm during development of Xenopus primordial germ cells
}

\author{
TAKESHI YAMAGUCHI*, AYAKA TAGUCHI, KENJI WATANABE and HIDEFUMI ORII* \\ Department of Life Science, University of Hyogo, Kamigori, Akou-gun, Hyogo, Japan
}

\begin{abstract}
Germes mRNA and protein are components of the germ plasm in Xenopus laevis. Previously, based on phenotypic observations of tailbud embryos expressing intact and mutant Germes, it was suggested that Germes is involved in the organization of germ plasm (Berekelya et al., 2007). Recently, to observe the germ plasm in a living embryo, we generated transgenic Xenopus expressing EGFP fused with a mitochondrial targeting signal, because germ plasm is enriched with mitochondria (Taguchi et al., 2012). Using this transgenic Xenopus, we demonstrate that Germes plays an essential role in the translocation of germ plasm from the cortex to the perinuclear region in primordial germ cells during early gastrulation.
\end{abstract}

KEY WORDS: PGC, germline, DEADSouth, mitochondrial cloud, chromatoid body

In early Xenopus development, the germline is generated by inheritance of specialized cytoplasm called 'germ plasm'. Germ plasm is present in the vegetal cortex of a fertilized egg, where it divides into about four blastomeres via the first two cleavages, and then distributes unequally to daughter cells until midblastula transition (MBT) (Taguchi et al., 2012; Whitington and Dixon, 1975). Early in gastrulation (stage 10), germ plasm translocates from the cortex to the perinuclear region in primordial germ cells (PGCs) and divides equally into two daughter PGCs in later cell divisions. The germ plasm contains electron dense granules, many mitochondria, and specific mRNAs and proteins. Recently, we demonstrated that germ plasm contains determinants that are necessary and sufficient for germline specification (Tada et al., 2012). To understand the mechanisms underlying germline specification in Xenopus, many RNA components of the germ plasm have been identified (Cuykendall and Houston, 2010; King etal., 2005), including GermesmRNA(Berekelya et al., 2003). The Germesgene is specifically expressed in the ovary. GermesmRNA has been detected in the entire cytoplasm of stage I oocytes and in the mitochondrial cloud of stage II oocytes. It is associated with the germ plasm until gastrulation and disappears after translocation to the perinuclear region. Germes encodes a protein with two leucine zipper motifs and an EF-hand motif (Berekelya et al., 2003). It has been shown that Germes protein also localizes to the germ plasm by expression of EGFP-tagged Germes protein in oocytes (Berekelya et al., 2007). A reduction in the number of PGCs has been observed in tailbud (stage 31-33) embryos overexpressing intact Germes (GermesWT) or Germes lacking both leucine zipper motifs (Germes $\Delta L Z s$ ). Interestingly, in these tailbud embryos, some PGCs are larger and found inside the endodermal mass, indicating that active PGC migration is blocked from an early stage. Using XpatmRNA and its protein as a germ plasm marker (Hudson and Woodland, 1998), it has been revealed that the germ plasm at stage 31-33 has a morphology similar to that at earlier stages. In addition, it has been shown that Germes protein interacts with dynein light chain 8 in vitro and in vivo (Berekelya et al., 2007). These findings suggest that Germes is involved in PGC migration and germ plasm organization.

The DEADSouthgene encodes DEAD-box RNA helicase belonging to the DDX25 family, and its transcript has also been identified as an RNA component of the germ plasm in Xenopus (MacArthur et al., 2000). Recently, we generated transgenic Xenopus expressing EGFP fused with a mitochondrial targeting signal (mito-EGFP) for observation of the germ plasm in living embryos (Taguchi et al., 2012), because germ plasm is enriched with mitochondria (Venkatarama et al., 2010; Elinson et al., 2011). Using mito-EGFP embryos, we demonstrated that DEADSouth protein localizes to the germ plasm, where it is required for proper $\mathrm{PGC}$ development (Yamaguchi et al., 2013). Interestingly, knockdown of DEADSouth mRNAcauses expansion of the germ plasm, inhibition of germ plasm translocation and division of PGCs after MBT. As a result, a reduc-

Abbreviations used in this paper: MBT, midblastula transition.

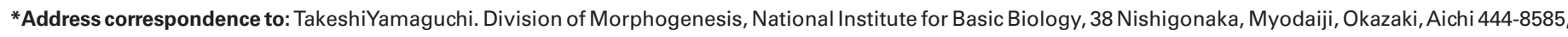

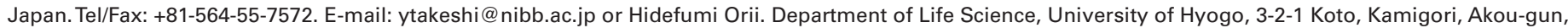
Hyogo 678-1297, Japan. Tel/Fax: +81-791-58-0187. E-mail: orii@sci.u-hyogo.ac.jp
} 
tion in the number of PGCs is observed in tailbud-stage embryos. The phenotype of DEADSouth-knockdown embryos is similar to that of embryos overexpressing GermesWT or Germes $\Delta L Z s$. To understand the mechanisms underlying germ plasm organization, it is important to investigate the phenotypes of embryos overexpressing GermesWT or Germes $\Delta L Z$ s for comparison with those of $D E A D S o u t h-k n o c k d o w n$ embryos, particularly at stages 7-12 that are much earlier than the tailbud stage. Although it has been very difficult to directly observe the germ plasm in isolated PGCs, the use of mito-EGFP Xenopus enables such observations (Taguchi et al., 2012; Yamaguchi et al., 2013). Here, we demonstrate that translocation of the germ plasm is inhibited by overexpression of GermesWT or Germes $\triangle L Z s$, and by knockdown of DEADSouth, suggesting that both Germes and DEADSouth proteins are involved in the translocation of germ plasm during MBT.

\section{Results and Discussion}

To investigate the function of Germes in PGC development, we generated three constructs, including intact Germes (GermesWT$D S$ ), Germes lacking the EF-hand motif (Germes $\triangle E F h-D S$ ), and Germes lacking both leucine zipper motifs (Germes $\Delta L Z s-D S$ ) according to Berekelya et al. (2007). To ensure PGC-specific expression, the open reading frames (ORFs) were followed by the 3' untranslated region (UTR) of the DEADSouth gene that is expressed in a PGC-specific manner (Kataoka et al., 2006). Each mRNA (460 pg) was co-injected into the vegetal pole of a fertilized egg with Venus-DEADSouth 3' UTR mRNA ( $v$-DS, $460 \mathrm{pg}$ ) as a PGC tracer (Kataoka et al., 2006). At stage 32, significantly reduced numbers of PGCs were observed in embryos injected with GermesWT-DS or Germes $\Delta L Z s-D S$, compared with those injected with only $v$-DS (GermesWT-DS, 9.2 \pm 3.2 ; Germes $\Delta L Z s-D S$, 10.5 \pm 3.5 ; and $v-D S, 17.9 \pm 2.6$ ) (Fig. 1 A-C,F). Embryos injected with $460 \mathrm{pg}$ Germes $\triangle E F h-D S$ mRNA showed no reduction in PGC numbers $(16.1 \pm 2.9)$ (Fig. $1 \mathrm{D}, \mathrm{F})$. These effects were identical to those described in a previous report in which PGCs were visualized by whole-mount in situ hybridization using the PGC-specific gene Xpat (Berekelya et al., 2007). Furthermore, we examined the effect of Germes $\triangle E F h-D S$ when twice the amount of mRNA (920 pg/embryo) was injected. Interestingly, Germes $\triangle E F h$-DSalso

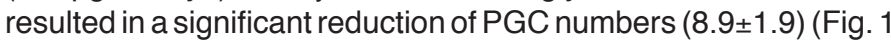
E,F), although the injected embryos developed normally. This result indicated that overexpression of GermesWT-DS, Germes $\Delta L Z s$ $D S$, and Germes $\triangle E F h-D S$ resulted in similar reductions of PGC numbers, but are different in terms of the magnitude of their effect. These differences might have occurred because Germes functions are regulated by multiple domains (see below).

Next, we used embryos from transgenic Xenopus expressing EGFP with the mitochondrial targeting signal (mito-EGFP) to examine the effects caused by overexpression of Germes-DS and Germes mutants. At stage 12, a significant reduction of PGC numbers was observed in mito-EGFP embryos injected with GermesWT-DS $(7.8 \pm 0.7, P<0.05)$ or Germes $\Delta L Z s-D S(6.3 \pm 1.9$, $P<0.01)$ mRNAs, compared with that in the control $(11.0 \pm 2.6)$. However, we did not observe significantly reduced PGC numbers in embryos injected with Germes $\triangle E F h-D S$, even at a dose of 920 pg/embryo (Fig. 1G). We also investigated the size distribution of PGCs at stage 12 (Fig. 2). The average diameters of PGCs from mito-EGFP embryos injected with GermesWT-DS (460 pg/ embryo), Germes $\Delta L Z s-D S$ (460 pg/embryo) or Germes $\triangle E F h$ - $D S$ (920 pg/embryo) were 59.6 $\pm 24.4 \mu \mathrm{m}, 56.9 \pm 21.2 \mu \mathrm{m}$ and $57.6 \pm 18.1$ $\mu \mathrm{m}$, respectively. The diameters of these PGCs were significantly larger than those of control PGCs $(48.4 \pm 8.0 \mu \mathrm{m})$. Moreover, these phenotypes were very similar to those of DEADSouth knockdown (Yamaguchi et al., 2013).

We also examined the morphology and intracellular localization of the germ plasm in PGCs from mito-EGFP embryos injected with GermesWT-DS or Germes mutant mRNAs. In uninjected PGCs,
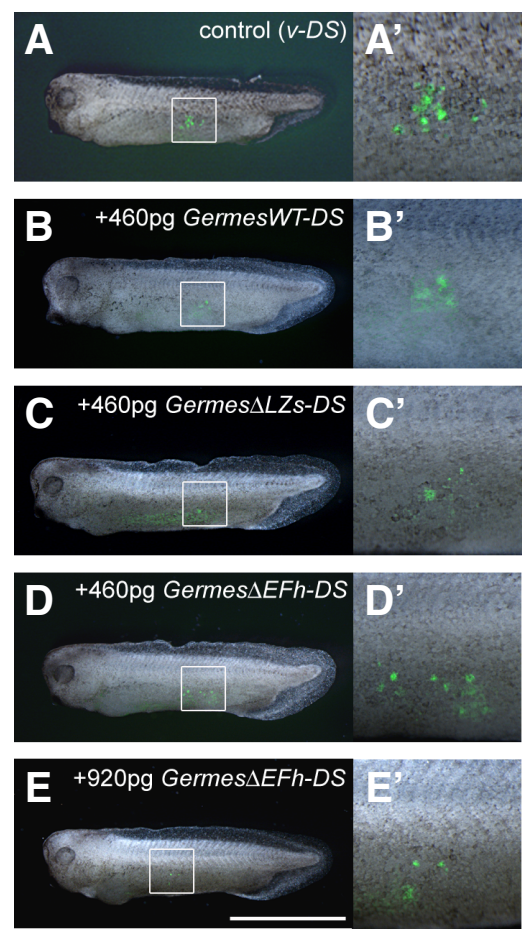

F

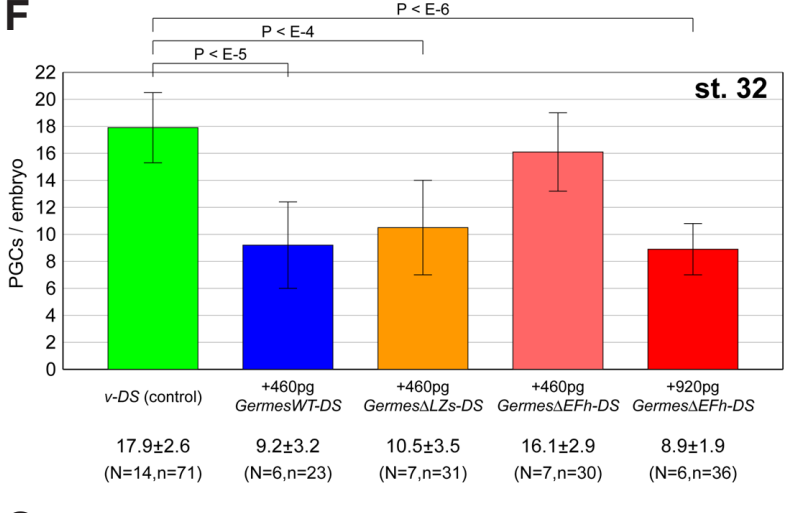

G

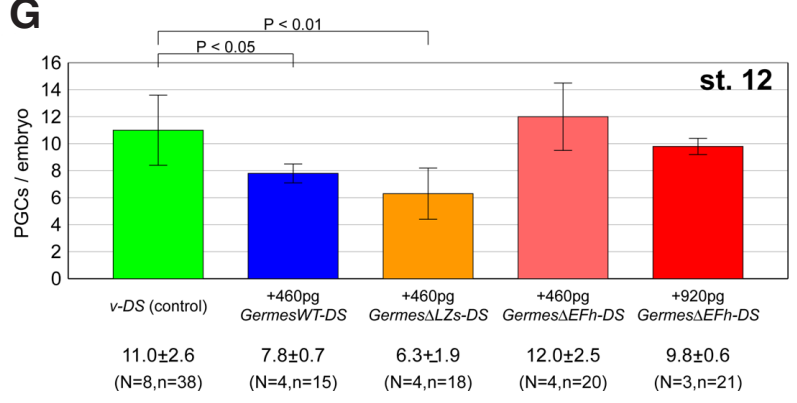

Fig. 1. Effect of overexpression of GermesWT-DS, Germes $\triangle L Z s-D S$ or Germes $\triangle E F h-D S$ in PGCs. (A-E) Representative examples of tailbud embryos injected with mRNA of v-DS only, v-DS plus GermesWT-DS, v-DS plus Germes $\Delta$ LZs$\mathrm{DS}$, or Germes $\Delta \mathrm{EFh}-\mathrm{DS}$, respectively. The amount of injected mRNA is indicated. Anterior is toward the left. Scale bar, $1 \mathrm{~mm}$. ( $\left.\mathbf{A}^{\prime}-\mathbf{E}^{\prime}\right)$ High magnifications of the areas indicated in (A-E), respectively. (F) The number of PGCs per embryo at stage 32 injected with the indicated mRNAs. PGC numbers were determined by externally counting from both sides. (G) The number of PGCs per embryo at stage 12. MitoEGFP transgenic embryos were injected with the indicated mRNAs, and then dissociated at stage 12. EGFP-positive and large cells were counted as PGCs. N and $n$ indicate the number of experiments and total embryos examined, respectively. Error bars indicate standard deviation. One-tailed P-values were calculated by the Student t-test for significance. 


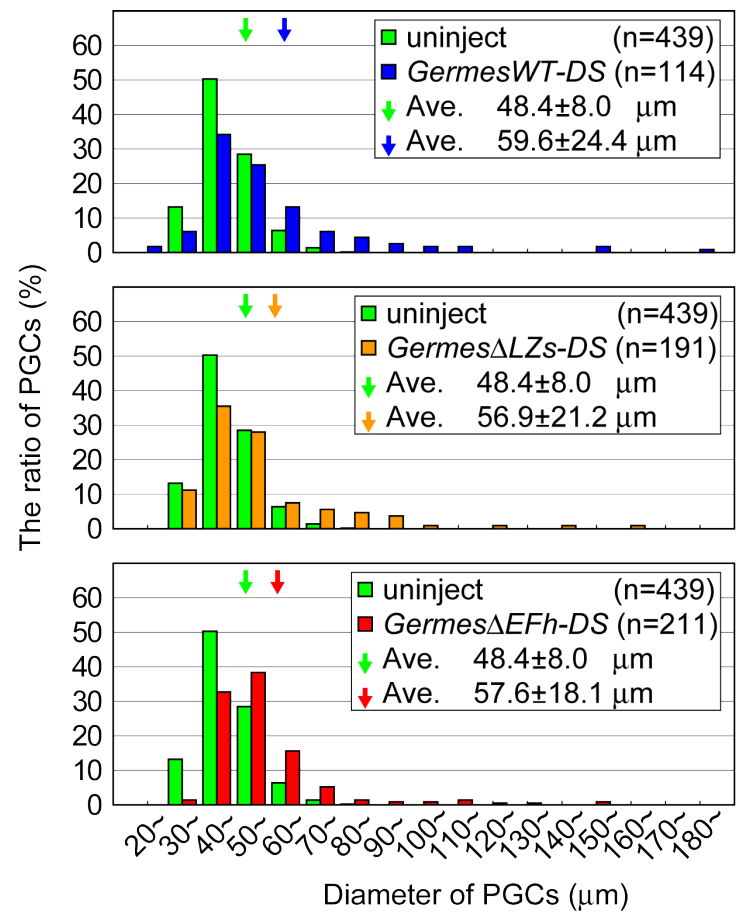

the germ plasm was present in the cortex at stage 7 , and then moved to the perinuclear region at stage 9. In embryos injected with GermesWT-DSor Germes mutants, many large PGCs, which retained the germ plasm in the cortex, were observed at stage 12
Fig. 2. Size distribution of PGCs from stage 12 embryos injected with GermesWT-DS, Germes $\triangle L Z s-D S$ or Germes $\triangle E F h-D S$ mRNAs. PGCs were isolated from the injected mito-EGFP embryos to measure their diameter. Total numbers of isolated PGCs (n) are shown as $100 \%$. The size distribution of PGCs in embryos injected with $460 \mathrm{pg}$ GermesWT-DS (blue), 460 pg Germes $\Delta$ LZs-DS (orange), or 920 pg Germes $\Delta$ EFh-DS (red) is compared with that in uninjected embryos (green). $n$ indicates total PGC numbers. Arrows indicate average diameters in the indicated experiments.

(Fig. 3A) in contrast to perinuclear localization of the germ plasm in most PGCs of uninjected embryos. Quantitative analysis demonstrated that $32.6 \%, 30.9 \%$ and $18.4 \%$ of PGCs in embryos injected with GermesWT-DS, Germes $\Delta$ LZs-DS or Germes $\Delta E F h-D S(920$ $\mathrm{pg})$, respectively, contained germ plasm in the cortex at stage 12, compared with only $6.8 \%$ of PGCs in uninjected embryos (Fig. 3B). These differences were significant $(P<0.01, U$-test). Interestingly, we could not detect any alteration in the PGCs of injected embryos until stage 7. The mislocalization of germ plasm in these PGCs was very similar to that in DEADSouth-knockdown PGCs (Yamaguchi et al., 2013). To elucidate the relationship among Germes, germ plasm translocation, and mitosis, we individually cultured PGCs isolated from stage 8 embryos injected with GermesWT-DS, and followed PGC mitosis for 11 hours (Fig. 4A). All five experiments (about 12 PGCs each/female/experiment) showed that mitosis of PGCs overexpressing GermesWT-DS was significantly inhibited compared with that in the control $(35.7 \pm 21.7 \%$ vs. $46.3 \pm 20.4 \%$; $P<0.05$, paired samples $t$-test). Interestingly, in non-dividing PGCs, mislocalization of germ plasm was observed more frequently in
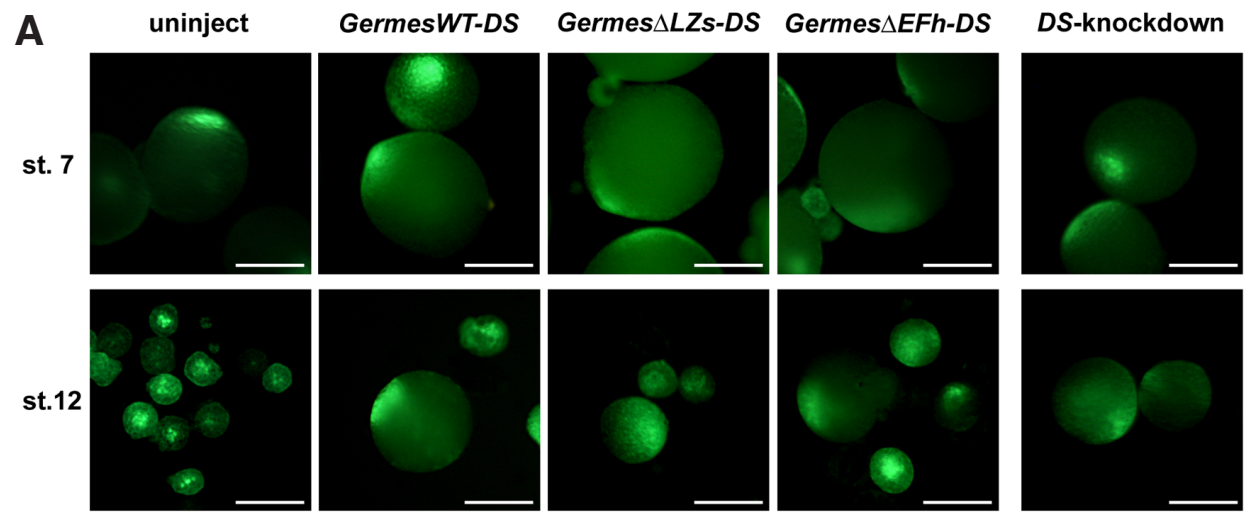

B
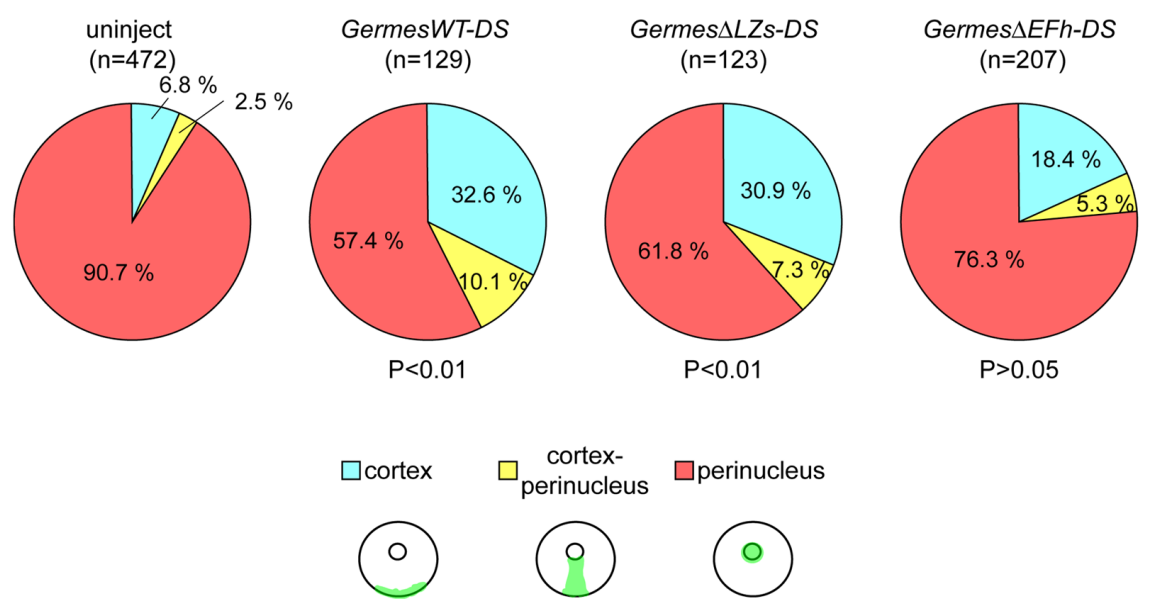

Fig. 3. Overexpression of GermesWT-DS, Germes $\Delta L Z s-D S$, or Germes $\Delta E F h-D S$ affects translocation of the germ plasm. (A) Localization of the germ plasm in PGCs isolated from mito-EGFP embryos at stages 7 (upper) and 12 (lower), which were injected with GermesWTDS (460 pg), Germes $\Delta$ LZs-DS (460 pg) or Germes $\Delta$ EFh-DS $(920$ pg) mRNAs. For comparison, PGCs from uninjected and DEADSouthknockdown (DS-knockdown; Yamaguchi et al., 2013) embryos are also shown. The images represent the severe phenotypes of PGCs in the experiment. Scale bars, $100 \mu \mathrm{m}$. Note that, at stage 12, PGCs overexpressing GermesWTDS, Germes $\Delta$ LZs-DS, or Germes $\Delta$ EFh-DS, and DS-knockdown PGCs are relatively large and contain the germ plasm beneath the cell membrane. (B) Ratio of PGCs with three localization patterns of germ plasm from stage 12 embryos uninjected or injected with GermesWT-DS 1460 pg), Germes $\Delta$ LZs-DS (460 pg) or Germes $\Delta$ EFhDS $(920$ pg) mRNAs. According to the localization patterns, PGCs were classified into three groups: cortex, perinucleus, and intermediate (cortex-perinucleus) as shown at the bottom of the panel. P-values were calculated by the Mann-Whitney U-test for significance. 
A
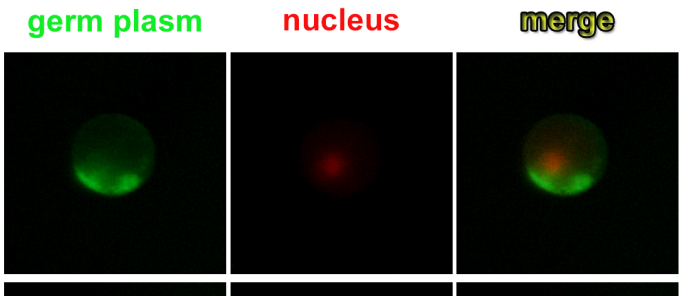

cortexperinucleus
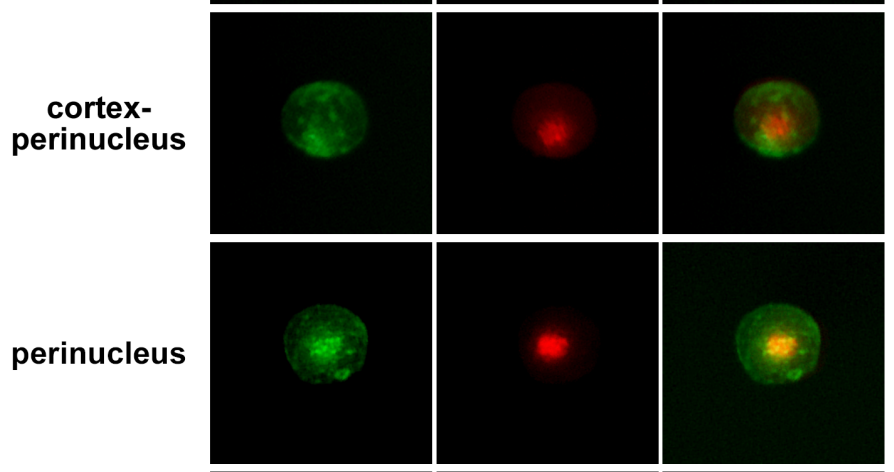

mitosis
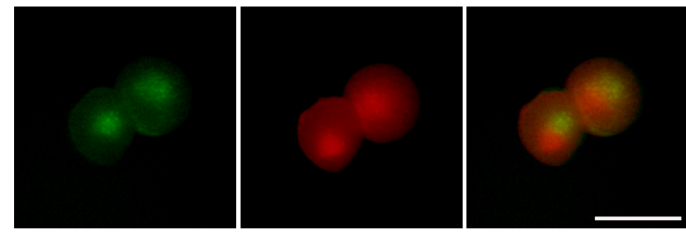

B
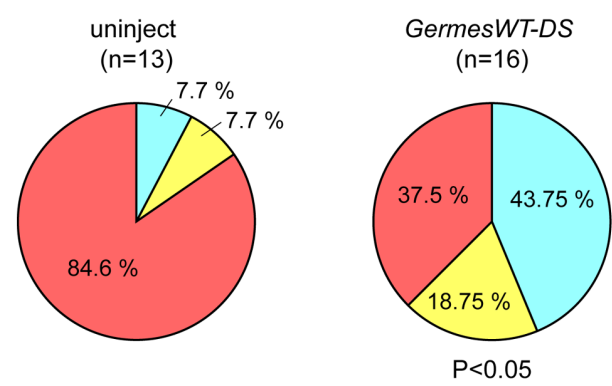

$\square$ cortex

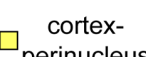

$\square$ perinucleus

Fig. 4. Overexpression of GermesWT-DS results in mitotic inhibition of PGCs with mislocalized germ plasm. (A) Behavior of germ plasm (green) during mitosis of a single cultured PGC from normal mito-EGFP transgenic embryos at stage 8 . Note that mitosis occurs after translocation of germ plasm from the cortex to the perinuclear region. Mitosis was observable at about 9 hours after isolation. Nuclei were labeled by injection of mCherry-NLS-DEADSouth 3' UTR mRNA (red). (B) Ratio of non-divided PGCs with three localization patterns of germ plasm after culture. The PGCs from stage-8 embryos uninjected or injected with GermesWT-DS $(460 \mathrm{pg})$ were cultured individually for 11 hours. Classification of nondivided PGCs and statistical analysis were performed as described in Fig. 3. Scale bar, $100 \mu \mathrm{m}$.

PGCs overexpressing GermesWT-DS than that in control PGCs (Fig. 4B). This difference was also significant $(P<0.05, U$-test). Conversely, perinuclear localization of the germ plasm was observed in all divided PGCs in control and overexpression of GermesWT-DS. Translocation of the germ plasm occurred prior to the initial equal division of PGCs after MBT. Taken together, these observations strongly suggested that abnormal translocation of germ plasm by overexpression of GermesWT-DS or Germes mutants resulted in inhibition of equal division of PGCs. It was likely that these large PGCs could not move normally in the endodermal mass as described previously (Berekelya et al., 2007). Based on observations of the PGCs from tailbud embryos (at stage 31-33) injected with GermesWTor Germes $\Delta$ LZs mRNAs, Berekelya et al., (2007) suggested that Germes is involved in the organization and functioning of germ plasm. In their study, it was unclear why overexpression of Germes $\triangle E F$ caused no phenotypic effects, because the EF-hand domain is thought to bind calcium ions to regulate physiological roles. Here, we demonstrated that overexpression of Germes $\triangle E F h$ also caused phenotypic effects similar to those of GermesWT or Germes $\Delta L Z s$ overexpression. The effects of their overexpression might be caused by competition for multiple Germes-interacting proteins including dynein light chain 8 (Berekelya et al., 2007).

Recently, we showed that translocation of the germ plasm is sensitive to nocodazole, but insensitive to cytochalasin $\mathrm{D}$, and that $\alpha$-tubulin is co-localized with germ plasm (Taguchi et al., 2012). These findings indicate that germ plasm translocates from the cortex to the perinuclear region through the microtubule system, but not the microfilament system. This observation is in good agreement with that of Germes protein interacting with dynein light chain 8 in vitro and in vivo (Berekelya et al., 2007). Germ plasm may be transported along microtubules to the perinuclear region by a dynein motor. However, the directionality of microtubules for germ plasm translocation remains to be determined.

It is very interesting that the phenotypes caused by overexpression of GermesWT, Germes $\Delta L Z s$, or Germes $\triangle E F h$ were very similar to those of $D E A D S o u t h$-depleted embryos. Because DEADSouth is an RNA helicase with some similarity to elF4A, it may be involved in translation of germ plasm-specific mRNAs (MacArthur et al., 2000). The subcellular region-specific translation of such mRNAs may be coupled to germ plasm translocation with Germes. Although we have not determined whether Germes associates with DEADSouth directly or indirectly, both proteins are obviously indispensable for proper maintenance and translocation of the germ plasm. After translocation, interactions between the germ plasm and nucleus would be required for germline specification. To understand the mechanisms underlying germline specification, it would be necessary to delineate more components of the germ plasm and their interactions with each other.

\section{Materials and Methods}

\section{Xenopus embryos}

Eggs and embryos from wild-type Xenopus laevis were prepared as described previously (Kataoka et al., 2006). Female transgenic Xenopus laevis expressing EGFP fused with a mitochondrial targeting signal (mitoEGFP) were also used in this study (Taguchi et al., 2012; Yamaguchi et al., 2013).

\section{Preparation of constructs}

The Germes ORF was amplified by a nested PCR method using ovarian cDNA from Xenopus laevis as a template, and was exchanged for the VenusORF of pCS2-Venus-DEADSouth 3'UTR(pCS2-Germes-DEADSouth 3'UTR). For the initial amplification, the sequences of the forward and reverse primers were CCTGTGACTCCTATATATGTGCTGGAACAT and CAAGTTTGGCATGTACAAGGTATACTCTGG, respectively. The PCR product was subjected to a secondary amplification using the nested forward and reverse primers, CTTTTTGCAGGATCCATGTGGCAAATGCTGAAATATGTGGT andCTCATCACTGAATTCTTAAGTATGGCTTAATTTTTGCGCCCT, respectively (sequences overlapping with the pCS2-VenusDEADSouth 3'UTR are underlined). pCS2-Germes $\triangle$ LZs-DEADSouth 3'UTR and pCS2-Germes $\triangle E F h-D E A D S o u t h$ 3'UTR constructs were generated by inverse PCR and In-Fusion technology (Clontech) using pCS2-Germes- 
DEADSouth 3'UTR as a template. The amino acid sequences of GermesWT, Germes $\Delta$ LZs and Germes $\Delta$ EFh used in this study were identical to those in a previous report by Berekelya et al., (2007).

\section{Preparation and microinjection of $m R N A$}

Template plasmids were linearized by digestion with Notl and used as templates for in vitro mRNA synthesis with an mMESSAGE mMACHINE SP6 kit (Ambion). The mRNA was microinjected into the cortical region at the vegetal pole of a fertilized egg with a Nonoject II microinjector (Drummond Scientific Company). Each mRNA (460 pg, $4.6 \mathrm{~nL}$ of $100 \mathrm{ng} / \mu \mathrm{L}$ mRNA) was injected into a fertilized egg. The same amount of $v-D S$ mRNA was co-injected as a PGC tracer.

\section{Observation of PGCs and germ plasm}

PGCs were observed and counted externally in $v$-DS-co-injected embryos at stage 32 (Kataoka et al., 2006). The PGCs were also isolated manually from dissociated transgenic embryos, counted, and examined for intracellular localization of the germ plasm (Yamaguchi et al., 2013). PGCs from stage 8-transgenic embryos were uninjected or injected with $460 \mathrm{pg}$ GermesWT-DSmRNA, and then individually seeded on $1 \%$ agarose-coated dishes containing 55\% Leibovitz's L-15 medium (Gibco) supplemented with $5 \%$ fetal bovine serum, and then cultured at $25^{\circ} \mathrm{C}$ for 11 hours. Germ plasm behavior was observed in PGCs from embryos injected with 460 pg mCherry-NLS (SV40 nuclear localization signal)-DEADSouth 3' UTR mRNA for nuclear staining (Taguchi et al., in preparation).

\section{Acknowledgements}

We thank the members of our laboratory, and particularly Dr. Makoto Mochii, for their support.

\section{References}

BEREKELYA, L.A., PONOMAREV, M.B., LUCHINSKAYA, N.N., BELYAVSKY, A.V. (2003). Xenopus Germes encodes a novel germ plasm-associated transcript. Gene Expr. Patterns 3: 521-524.
BEREKELYA, L.A., MIKRYUKOV, A.A., LUCHINSKAYA, N.N., PONOMAREV, M.B., WOODLAND, H.R., BELYAVSKY, A.V. (2007). The protein encoded by the germ plasm RNA Germes associates with dynein light chains and functions in Xenopus germline development. Differentiation 75: 546-558.

CUYKENDALL, T.N., HOUSTON, D.W. (2010). Identification of germ plasm-associated transcripts by microarry analysis of Xenopus vegetal cortex RNA. Dev. Dyn. 239: 1838-1848.

ELINSON, R.P., SABO, M.C., FISHER, C., YAMAGUCHI, T., ORII, H., NATH, K. (2011). Germ plasm in Eleutherodactylus coqui, a direct developing frog with large eggs. EvoDevo 2: 20.

HUDSON, C., WOODLAND, H.R. (1998). Xpat, a gene expressed specifically in germ plasm and primordial germ cells of Xenopus. Mech. Dev. 73: 159-168.

KATAOKA, K., YAMAGUCHI, T., ORII, H., TAZAKI, A., WATANABE, K., MOCHII, M. (2006). Visualization of the Xenopus primordial germ cells using a green fluorescent protein controlled by cis elements of the 3' untranslated region of DEADSouth gene. Mech. Dev. 123: 746-760.

KING, M.L., MESSITT, T.J., MOWRY, K.L. (2005). Putting RNAs in the right place at the right time: RNA localization in the frog oocytes. Biol. Cell 97: 19-33.

MACARTHUR, H., HOUSTON, D.W., BUBUNENKO, M., MOSQUERA, L., KING, M.L. (2000). DEADSouth is a germ plasm specific DEAD-box RNA helicase in Xenopus related to elF4A. Mech. Dev. 95: 291-295.

TADA, H., ORII, H., MOCHII, M., WATANABE, K. (2012). Ectopic formation of primordial germ cells by transplantation of the germ plasm: direct evidence for germ cell determinant in Xenopus. Dev. Biol. 371: 86-93.

TAGUCHI, A., TAKII, M., MOTOISHI, M., ORII, H., MOCHII, M., WATANABE, K. (2012) Analysis of localization and reorganization of germ plasm in Xenopus transgenic line with fluorescence-labeled mitochondoria. Dev. Growth Differ. 54: 767-776.

VENKATARAMA, T., LAI, F., LUO, X., ZHOU, Y., NEWMAN, K., KING, M.L. (2010). Repression of zygotic gene expression in the Xenopus germline. Development 137: 651-660.

WHITINGTON, P.M., DIXON, K.E. (1975). Quantitative studies of germ plasm and germ cells during early embryogenesis of Xenopus laevis. J. Embyol. Exp. Morph. 33: 57-74.

YAMAGUCHI, T., TAGUCHI, A., WATANABE, K., ORII, H. (2013). DEADSouth protein localizes to germplasm and is required for the development of primordial germ cells in Xenopus laevis. Biol. Open 2: 191-199. 


\section{Further Related Reading, published previously in the Int. J. Dev. Biol.}

Natural and artificial routes to pluripotency

Winfried H. Krueger, Lindsey C. Swanson, Borko Tanasijevic and Theodore P. Rasmussen Int. J. Dev. Biol. (2010) 54: 1545-1564

Maternal RNAs encoding transcription factors for germline-specific gene expression in Drosophila embryos

Jun Yatsu, Makoto Hayashi, Masanori Mukai, Kayo Arita, Shuji Shigenobu and Satoru Kobayashi Int. J. Dev. Biol. (2008) 52: 913-923

The formation of primordial germ cells from germline cells in spherical embryos derived from the blastodisc of 2-cell embryos in goldfish, Carassius auratus

Satoshi Otani, Tomoe Kitauchi, Taiju Saito, Suzu Sakao, Shingo Maegawa, Kunio Inoue, Katsutoshi Arai and Etsuro Yamaha

Int. J. Dev. Biol. (2005) 49: 843-850

Primordial germ cell migration

Kathleen Molyneaux and Christopher Wylie

Int. J. Dev. Biol. (2004) 48: 537-543

Primordial germ cell development: is the urodele pattern closer to mammals than to anurans?

M Wakahara

Int. J. Dev. Biol. (1996) 40: 653-659

5 yr ISI Impact Factor $(2011)=2.959$

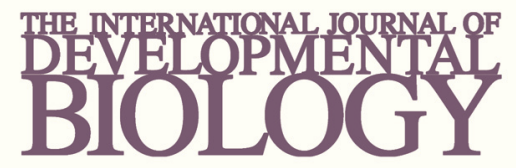

Volume 54 Nos. 6/7
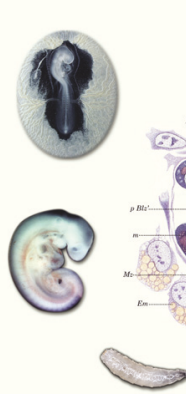

Developmental Hematopoiesis
Special Issue

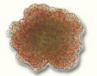

कर
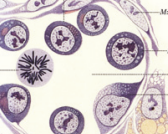

(2)

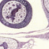

(2)
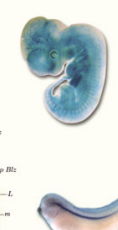

(
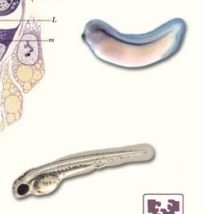

5

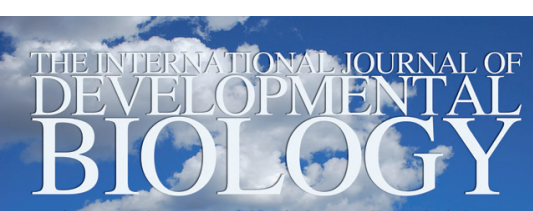

Volume 56 Nos. 10/11/12-Special Issue

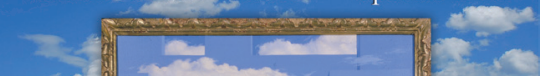

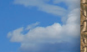

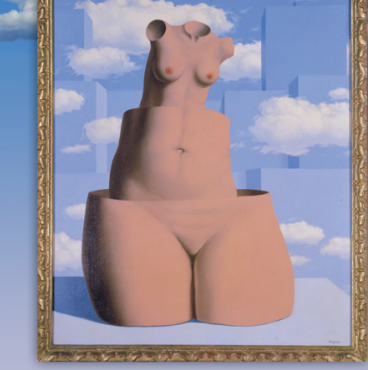

Female Germ Cells in Development \& Tumors

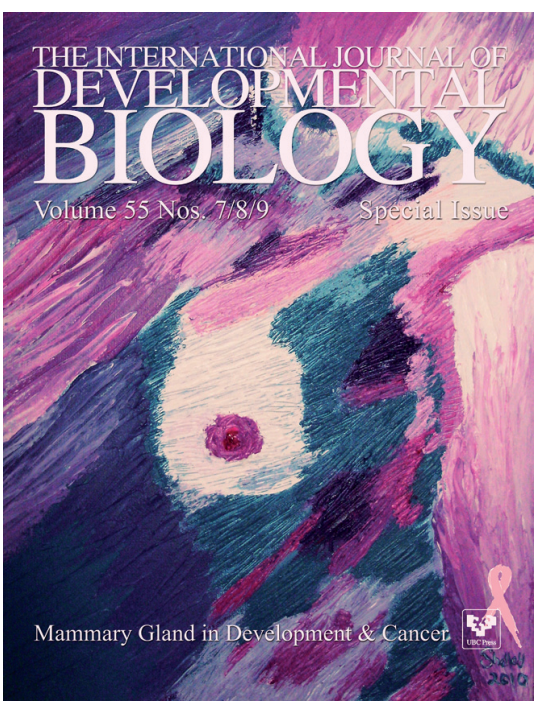

THE INTERNATIONAL JOURNAL OF DEVELOPMENIAI

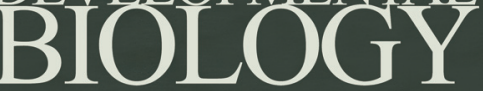

Volume 55 Nos. $4 / 5$

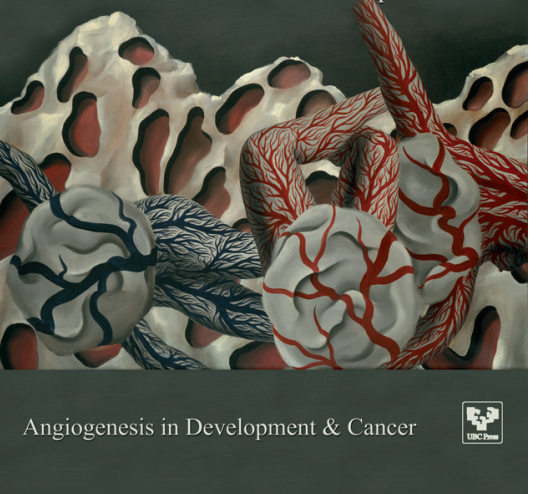

